\title{
Análise Termodinâmica do Comportamento Mecânico na Região Elástica de Blendas de Poli(Tereftalato de Etileno) Reciclado e Poliolefinas Recicladas
}

\author{
José M. Marconcini \\ Instituto de Tecnologia para o Desenvolvimento, UFPR \\ Adhemar Ruvolo Filho \\ Departamento de Química, UFSCar
}

\begin{abstract}
Resumo: Este trabalho descreve o estudo de blendas de poli(tereftalato de etileno) reciclado e poliolefinas recicladas, com e sem adição de polipropileno funcionalizado com anidrido maleico e poli(etileno-co-octeno-1) utilizando ensaios mecânicos e microscopia eletrônica de varredura. Foi aplicado um formalismo termodinâmico com base na função trabalho de Helmholtz para o comportamento mecânico na região elástica, correlacionando-se com o armazenamento de energia elástica para os materiais estudados. Também foi analisada a dissipação de energia relativa ao fenômeno elasto-plástico na região de baixas deformações. Para as blendas estudadas, observou-se que o armazenamento de energia e o efeito do compatibilizante são muito mais acentuados na região rica em poliolefinas, corroborando com as imagens da morfologia observadas via microscopia eletrônica. A análise termodinâmica apresentada mostrou-se uma ferramenta útil e confiável e de baixo custo, para avaliar o efeito de compatibilização de sistemas poliméricos imiscíveis. No presente trabalho, particularmente para a avaliação do comportamento mecânico de misturas de materiais "commodities" reciclados.
\end{abstract}

Palavras-chave: Blendas PET/poliolefinas reciclados, compatibilização, propriedades mecânicas, análise termodinâmica, $M E V$.

\section{Thermodynamic Analysis of Mechanical Behaviour in the Elastic Region of Blends of Recycled Poly(ethylene terephthalate)} and Recycled Polyolefins

\begin{abstract}
This work describes the study using mechanical tests with the blend of recycled poly(ethylene terephthalate) (PET) and recycled polyolefin with and without the addition of polypropylene grafted with maleic anhydride and poly(ethyleneco-octene-1). A thermodynamic approach based on the Helmholtz work function was applied in the analysis of mechanical tests, correlating the effects of energy storage and from the compatibilizer on the elastic region of the materials. For the system studied, the polyolefin-rich region shows higher storage of elastic energy corroborating the morphology images obtained from SEM analysis. The thermodynamic analysis seems a useful tool to evaluate the compatibilizer effect in polymeric immiscible blends. In this work, more specifically, this method was used to analyze the mechanical behavior of different compositions of recycled polymeric commodity materials.
\end{abstract}

Keywords: Blends PET/polyolefin recycled, compatibilization, mechanical properties, thermodynamic analysis, SEM.

\section{Introdução}

Poliolefinas, tais como polietileno de alta densidade (PEAD), polietileno de baixa densidade (PEBD) e polipropileno (PP) e poliésteres, como o poli(tereftalato de etileno) (PET) são as duas classes de termoplásticos mais consumidas e que estão disponíveis em grandes quantidades a partir do descarte doméstico ${ }^{[1,2]}$, sendo desafiadora, tecnológica e ambientalmente correta, a reciclagem destes materiais e sua caracterização mecânica antevendo a possibilidade de um novo ciclo de vida na forma de novos produtos.

Uma opção viável de reciclagem é a mistura de poliolefinas recicladas e PET reciclado para produzir blendas, que é um importante método de se obter novos materiais e/ou modificar as características de um determinado polímero $^{[3,4]}$.

As blendas de PET com poliolefinas podem oferecer um balanço atrativo de propriedades mecânicas, de barreira e de processabilidade. Porém, a imiscibilidade entre estas duas classes de polímeros, poliésteres e poliolefinas, leva à formação de blendas com pobre adesão e alta tensão interfacial, com uma grosseira separação de fases, resultando em pobres propriedades mecânicas e de barreira ${ }^{[1,5-7]}$.

Para melhorar estas propriedades, torna-se necessário limitar a formação de fases segregadas na blenda durante a etapa de mistura, adicionando ou formando in situ um terceiro componente que atue como compatibilizante na interface dos dois polímeros. Deste modo, obtêm-se resultados 
com uma fina dispersão de fases e melhora nas propriedades das blendas ${ }^{[4,8-10]}$.

A literatura de blendas de PET com poliolefinas tem se desenvolvido de maneira marcante, com vários artigos se referindo a diferentes faixas de concentração de blendas, diferentes tipos de compatibilizantes utilizados para este sistema, diferentes equipamentos e métodos de processamento, e blendas dos polímeros virgens, virgem com reciclado, e somente materiais reciclados. Uma das principais técnicas de caracterização presente em vários artigos é o ensaio mecânico de tração para a avaliação das propriedades mecânicas da blenda, destacando-se a deformação na ruptura.

Neste artigo, realizou-se uma breve revisão histórica dos trabalhos que consideramos mais relevantes com relação a blendas de PET com poliolefinas, com um enfoque nas propriedades mecânicas.

De maneira geral, observou-se nos artigos citados que as propriedades mecânicas não são analisadas sob um ponto de vista termodinâmico, o que poderia contribuir com uma interpretação de como a energia mecânica fornecida a um polímero se distribui sob a forma de variação da energia interna e sob variação da energia conformacional, e relacionar estas propriedades com os fenômenos de compatibilização, levando a uma nova compreensão do efeito da adição do compatibilizante.

O PET foi sintetizado em 1941 e, de acordo com Utracki $^{[11]}$, sob um ponto de vista histórico da literatura de patentes, a primeira blenda de PET com polietileno surge no final da década de 1960 para melhoria da resistência ao impacto, com polímeros virgens.

Em 1983, Traugott e colaboradores ${ }^{[12]}$ publicaram um estudo da blenda PET/PEAD em várias composições com polímeros virgens, mostrando a partir de ensaios mecânicos de tração a dependência das propriedades mecânicas da blenda com a composição e uma redução destas propriedades em relação às matérias primas originais, devido a incompatibilidade entre os polímeros. No entanto observou-se um aumento destas propriedades ao se adicionar diferentes tipos de compatibilizantes. Destacou-se com melhor desempenho as blendas compatibilizadas com $20 \%$ de copolímero estirenoetileno 1-buteno hidrogenado-butadieno-estireno (SEBS).

Halder e colaboradores ${ }^{[13]}, 1989$, estudaram o sistema de polímeros virgens $\mathrm{PET} /$ policarbonato (PC)/polipropileno (PP), verificando por DSC que o PET e o policarbonato eram miscíveis, enquanto o polipropileno era incompatível à fase PET/PC. Mantendo-se a proporção entre PET e PC, e variando-se a quantidade de PP, observou-se que as propriedades mecânicas de tração e flexão diminuíram com a adição de PP. A resistência ao impacto com entalhe aumentou até um certo nível e depois diminuiu com a adição de PP, enquanto que sem entalhe a resistência ao impacto diminuiu gradualmente.

Carté e Moet ${ }^{[8]}$, estudaram blendas de PET/PEAD a partir de materiais virgens com vários compatibilizantes comerciais, preparadas em extrusora dupla rosca. Os autores ob- servaram uma melhoria das propriedades mecânicas com a adição de compatibilizantes, com efeito marcante na deformação na ruptura. $\mathrm{O}$ melhor resultado foi obtido para $20 \mathrm{pcr}$ de SEBS-g-MA, com $2 \%$ de anidrido maleico (MA), com valor de elongação na ruptura em torno de $600 \%$, enquanto para as demais concentrações deste e de outros compatibilizantes esta propriedade situou-se sempre abaixo de $125 \%$.

Dagli e Kamdar ${ }^{[14]}$, estudaram o efeito da seqüência de adição dos componentes na compatibilização reativa de blendas PET/PEAD, usando polímeros virgens e o etileno glicidil metacrilato (EGMA) como compatibilizante. Avaliaram a morfologia das blendas e observaram que sequiências de mistura dos componentes durante a extrusão onde o componente reativo foi agrupado inicialmente com o componente apolar da blenda resultaram nas melhores compatibilizações.

Ballauri e colaboradore ${ }^{[15]}$, em 1996, apresentaram um trabalho sobre blendas de PET reciclado/PP reciclado variando-se a concentração do compatibilizante comercial SEBS-g-MA na faixa de 0 a $10 \%$. Os autores observaram uma melhoria nas propriedades mecânicas e na morfologia, e que pequenas quantidades deste compatibilizante induzem a uma transição de frágil para dúctil com grande melhoria da deformação na ruptura e na resistência ao impacto.

La Mantia ${ }^{[16]}$, estudou uma blenda composta de plásticos reciclados de embalagens de líquidos, com a composição aproximada de PET 45\%/PE 35\%/PVC 20\%, sem e com a adição de compatibilizantes. Os compatibilizantes que apresentaram melhores resultados foram o SEBS e o etileno propileno monômero dieno (EPDM), aumentando a resistência à tração em relação à mistura sem compatibilizantes.

Pacheco e Hemais ${ }^{[17]}$, apresentaram um estudo mercadológico para uma blenda PET 75\%/PEAD 25\%/ionômero, avaliando as potencialidades do mercado brasileiro para polímeros reciclados e a utilização desta blenda em embalagens sem contato com alimentos, tais como produtos de limpeza, tintas, óleo de linhaça e tanques de combustível de automóveis.

Santos e colaboradores ${ }^{[18]}$, estudaram a influência de resíduos catalíticos na degradação de plásticos reciclados, blenda de PEAD/PP e PET, provenientes de resíduos urbanos. Foram utilizados infravermelho e calorimetria exploratória diferencial (DSC) no estudo das poliolefinas e medidas de viscosidade intrínseca e titulação de grupos funcionais no estudo do PET. Na degradação das poliolefinas, foi observada a influência de rótulos e tampas de polietileno de baixa densidade e de polipropileno. Foi observada uma forte influência dos adesivos na degradação do PET.

Iñiguez e colaboradores ${ }^{[19]}$, avaliaram a morfologia e as propriedades mecânicas de blendas PET/PEAD ambos reciclados, com e sem a utilização de compatibilizante; copolímero estireno-etileno 1-buteno hidrogenado-butadieno-estireno (SEBS) (Kraton G-1652), processando os materiais em misturador de câmara interna e em extrusora dupla rosca. Os autores concluem que o compatibilizante reduz a mobilidade interfacial, os efeitos de coalescência e estabiliza a morfolo- 
gia, sendo a propriedade mecânica com maior modificação a deformação na ruptura. Obtiveram bons resultados na fase rica em PEAD.

Dimitrova e colaboradores ${ }^{[5]}$, sintetizaram uma série de copoliésteres e os utilizaram como compatibilizantes de blendas de polímeros virgens PET/PEAD. Também utilizaram como compatibilizante uma borracha termoplástica comercial funcionalizada com anidrido maleico (Kraton FG 1901X). Realizaram avaliação reológica e mecânica das blendas, obtendo um aumento na deformação na ruptura para todas as blendas compatibilizadas, obtendo o melhor resultado a blenda com o compatibilizante comercial.

Guerrero e colaboradores ${ }^{[20]}$, estudaram a blenda PET/ PEAD com polímeros virgens, sem e com a adição de um compatibilizante um copolímero de etileno e ácido metacrilíco parcialmente neutralizado com zinco (Surlyn). O efeito do compatibilizante observado pelos autores nas propriedades mecânicas da blenda foi de aumento na deformação na ruptura e na resistência ao impacto.

$\mathrm{Kim}^{[21]}$ e colaboradores, utilizaram compatibilizantes com o grupo isocianato para blendas de polímeros virgens PET/PEAD e avaliaram a morfologia e propriedades mecânicas das blendas com e sem compatibilizante. Observaram aumento na resistência à tração e na deformação na ruptura das blendas após a adição do compatibilizante.

Lusinchi ${ }^{[1]}$ e colaboradores, realizaram a compatibilização reativa de blendas PET/PEAD na composição 60/40, a partir dos materiais virgens, com a adição de 0 a $2 \%$ de anidrido maleico (MA) sem a adição de iniciadores de radicais livres em um misturador de câmara fechada. Os autores observaram que a resistência à fratura atingiu o valor máximo a partir da adição de $1 \%$ de anidrido maleico e praticamente permaneceu constante para porcentagens maiores deste compatibilizante. A deformação na ruptura passa por um máximo igual a $35 \%$ com a adição de $0,5 \%$ de MA, caindo para um patamar de $25 \%$ para adições maiores do compatibilizante.

Papke e Karger-Kocsis ${ }^{[22]}$ em 2001, estudaram blendas de polímeros virgens PET com vários elastômeros termoplásticos, a maioria olefínicos, realizando cura dinâmica dos materiais para a estabilização da morfologia. Os melhores resultados foram obtidos com borracha nitrílica, com alto teor de acrilonitrila, com o copolímero etileno glicidil metacrilato (EGMA) ou borracha etileno propileno funcionalizado com glicidil metacrilato (EPR-g-GMA). Observaram que foi negligenciável o efeito da cura dinâmica na melhoria de propriedades mecânicas das blendas.

Shertukde e Kale ${ }^{[23]}$ em 2001 estudaram a blenda PET/ PEAD, com PET proveniente de garrafas descartadas, PET virgem e PEAD. Utilizaram como compatibilizantes o copolímero etileno ácido acrílico (EAA) e o polipropileno funcionalizado com anidridrido maleico (PP-g-MA). Avaliaram as propriedades mecânicas por ensaio de tração e propriedades de barreira, tais como permeabilidade a oxigênio e permeabilidade a vapor d'água. Os autores observaram que as propriedades mecânicas da blenda sem compatibilizantes mos- traram-se inferiores às compatibilizadas. As concentrações de 5 pcr de EAA e 2,5 pcr de PP-g-MA foram as que produziram melhores resultados, sendo que com 5 pcr de EAA as propriedades foram melhores.

Torres e colaboradores ${ }^{[9]}$ em 2001 apresentaram um estudo de compatibilização reativa em blendas de PET/PEAD com polímeros virgens. Foram utilizados dois compatibilizantes preparados via extrusão reativa contendo 1,2 ou 2,3\% em massa de glicidil metil acrilato (GMA) na forma de HDPE-g-GMA e um copolímero estatístico contendo $1 \%$ em massa de GMA na forma etileno-metil acrilato-glicidil metil acrilato (70:29:1\% em massa) denominado Lotader AX8920. A composição estudada foi de PET 30\%/PEAD 70\% com adição de 5\% de compatibilizante, obtendo-se o resultado mais pronunciado com o copolímero estatístico, para o qual a deformação na ruptura e a resistência ao impacto aumentaram em 100\% em relação à blenda sem compatibilizante.

Pluta e colaboradores ${ }^{[6]}$, em 2001, apresentaram um estudo de blendas de PET e PEAD, ambos polímeros reciclados, compatibilizados com SEBS-g-MA e EGMA, em função da quantidade de compatibilizantes. As análises reológica, microscópica e análise térmica dinâmico-mecânica forneceram subsídios de interação entre as fases e compatibilização do sistema. Com base nos resultados dinâmico-mecânicos, os autores sugerem que a concentração ideal de compatibilizante é próxima a 5\% em massa.

Avila e colaboradores ${ }^{[24]}$, estudaram a blenda de materiais reciclados PET 60\%/PEAD $40 \%$ sem a adição de compatibilizantes, processando os materiais abaixo da temperatura de fusão do PET, denominando o sistema como material compósito particulado. Foi avaliado o efeito de vários reprocessamentos nas propriedades mecânicas da blenda. Os autores propõem uma forma de cálculo do módulo elástico em função do número de reprocessamentos. As curvas resultantes dos ensaios mecânicos de tração apontam para um material frágil com valores de deformação na ruptura entre 4 e $8 \%$ em função do número de reprocessamentos.

Xu e colaboradores ${ }^{[25]}$ em 2005 apresentaram um estudo do comportamento reológico de blendas microfibrilares de $\mathrm{PET} / \mathrm{PEAD}$ e PC/PEAD, com polímeros virgens, sendo que a porcentagem em massa de poliéster(PET ou PC) variou entre 10 a $30 \%$. As morfologias das blendas mostram que a fase dispersa, (PET ou PC) apresenta o formato de microfibrilas após o processamento. $\mathrm{O}$ resultado reológico mais relevante é que acima da temperatura de fluxo da fase microfibrilar da blenda PC/PEAD, a viscosidade da blenda é menor do que as viscosidades do PEAD e do PC, contradizendo o esperado teoricamente.

Herrera-Franco e colaboradores ${ }^{[26]}$ em 2006 publicaram estudo sobre blendas de PET/PEAD de materiais virgens em que o PEAD previamente à extrusão, foi oxidado por radiação gama visando a compatibilização entre os polímeros. As propriedades dinâmico-mecânicas foram avaliadas e foi observado que o maior aumento ocorreu entre 10 e $20 \%$ de PET. 
Em função do estado da arte apresentado, tem-se neste trabalho como objetivo a contribuição com uma abordagem termodinâmica dos ensaios mecânicos sob tração de materiais poliméricos. Para isto, aplicou-se um formalismo termodinâmico para análise do comportamento mecânico na região elástica, diferentemente dos artigos apresentados anteriormente, onde a análise principal ficou restrita a região de deformação plástica, destacando-se a deformação na ruptura. A partir da abordagem termodinâmica na região elástica pretende-se efetuar uma interpretação dos ensaios mecânicos com uma compreensão das contribuições da variação da energia interna e da variação da energia conformacional na energia mecânica deformacional que o polímero armazena durante a realização de esforços mecânicos sobre o material ainda dentro do regime elástico.

\section{Aspectos Termodinâmicos Aplicados ao Ensaio Mecânico de Tração de Materiais Poliméricos: Variação da Função Trabalho de Helmholtz $(\Delta A)$, da Energia Interna $(\Delta \mathrm{U})$ e da Entropia Conformacional $(\Delta S)$}

Segundo Tager ${ }^{[27]}$, o estado de equilíbrio de uma cadeia flexível corresponde ao formato enovelado. Se tais cadeias são estendidas por forças externas, os movimentos térmicos das unidades das cadeias irão atuar contra as forças externas.

Com base na termodinâmica, para um processo ocorrendo a volume e temperatura constantes, a variação de energia livre de Helmholtz (dA) está relacionada com a variação da energia interna (dU) e a entropia (dS) pela expressão:

$$
\mathrm{dA}=\mathrm{dU}-\mathrm{Td} \mathrm{S}
$$

De outro lado, dA é o trabalho útil realizado no sistema. Se este trabalho for um trabalho de tração, então $\mathrm{dA}=\mathrm{fdl}$, onde f é a força e dl a variação no comprimento do corpo de prova. Logo, fdl $=\mathrm{dU}-\mathrm{TdS}$, ou

$$
f=\left(\frac{\partial U}{\partial l}\right)_{T}-T\left(\frac{\partial S}{\partial l}\right)_{T}
$$

A partir da Equação 4, observa-se que pode haver dois tipos de forças elásticas: uma associada à variação da energia interna e outra com a variação da entropia e com o movimento térmico.

Na deformação de um cristal ideal, as variações nos arranjos relativos de seus íons ou átomos são muito pequenas e podem ser negligenciadas e portanto o termo $\left(\frac{\partial S}{\partial l}\right)_{T}=0$.

Logo, $f=\left(\frac{\partial U}{\partial l}\right)_{T}$, isto é o trabalho realizado por uma força externa deformando o corpo de prova só altera a energia interna. A deformação de um cristal ideal é puramente energética em sua natureza.

A deformação de uma borracha ideal não envolve variação da energia interna e portanto $\left(\frac{\partial U}{\partial l}\right)_{T}=0$. Logo, a defor- mação da borracha ideal dependerá somente do termo - $\mathrm{T}(\delta \mathrm{S} /$ $\delta 1)$, isto é, da temperatura e da variação da entropia. Ao se deformar, a borracha passa de um estado inicial não perturbado, de maior entropia, para um estado alongado, em que as cadeias poliméricas mudam de conformação, de menor entropia. A deformação de uma borracha ideal, à temperatura constante, será puramente entrópica em sua natureza.

O diagrama esquemático tensão - deformação, mostrado na Figura 1, representa a resposta mecânica típica para um material polimérico semicristalino.

Na região elástica do ponto $(0 ; 0)$ até a tensão de escoamento $\left(\sigma_{\mathrm{E}} ; \varepsilon_{\mathrm{E}}\right)$, para pequenas deformações, é válido considerar que a variação da energia interna $\Delta \mathrm{U}$ seja diretamente proporcional ao quadrado da distância de equilíbrio da posição dos átomos, isto é, $\Delta \mathrm{U}=\mathrm{c}_{1}\left(\mathrm{r}-\mathrm{r}_{0}\right)^{2}$, onde $\mathrm{r}_{0}$ é a posição inicial dos átomos, $\mathrm{r}$ o deslocamento em relação à posição inicial dos átomos e $\mathrm{c}_{1}$ a constante de proporcionalidade. Logo, a força elástica $f$ devido à variação da posição $\mathrm{r}$ é $\mathrm{f}=(\mathrm{d} \Delta \mathrm{U} / \mathrm{dr})=2 \mathrm{c}_{1}\left(\mathrm{r}-\mathrm{r}_{0}\right)$. A tensão $\sigma$ é dada pela razão força / área, $\operatorname{logo}, \sigma=$ f/área $=\left(2 \mathrm{c}_{1} /\right.$ área $)\left(\mathrm{r}-\mathrm{r}_{0}\right)=\left(2 \mathrm{c}_{1} \mathrm{r}_{0}\right.$ /área $)$ $\left(\mathrm{r}-\mathrm{r}_{0}\right) / \mathrm{r}_{0}=\mathrm{E} \varepsilon$, sendo o módulo elástico $\mathrm{E}$ dado por $\mathrm{E}=\left(2 \mathrm{c}_{1}\right.$ $\mathrm{r}_{0} /$ área), sendo a deformação $\varepsilon$ igual a $\left(\mathrm{r}-\mathrm{r}_{0}\right) / \mathrm{r}_{0}$.

Portanto, o diagrama tensão $(\sigma)$ - deformação $(\varepsilon)$ deve apresentar uma relação linear, $\sigma=\mathrm{E} \varepsilon$. Ao se realizar trabalho mecânico no material à temperatura constante, este armazena a energia elástica deformacional $(\Delta \mathrm{A})$ de duas maneiras: aumentando a variação da energia interna $(\Delta \mathrm{U}>0)$ ou diminuindo a variação de entropia $(\Delta \mathrm{S}<0)$, uma vez que $\Delta \mathrm{A}=\Delta \mathrm{U}-\mathrm{T} \Delta \mathrm{S}$. Para pequenas deformações, na região elástica, é possível considerar-se que a deformação referese apenas ao distanciamento dos átomos da rede cristalina e, portanto a variação entrópica deveria tender a zero, isto é, $\Delta \mathrm{A}=\Delta \mathrm{U}$. Este fenômeno, na Figura 1, corresponde à região entre os pontos $(0,0)$ e $\mathrm{B}$, onde $\sigma=\mathrm{E} \varepsilon$. A observação de desvios desta linearidade representa que no material ocorrem mecanismos de absorção da energia deformacional relativos à contribuição do termo entrópico $(-\mathrm{T} \Delta \mathrm{S})$ e distintos daqueles relativos apenas ao aumento da energia interna $\Delta \mathrm{U}$.

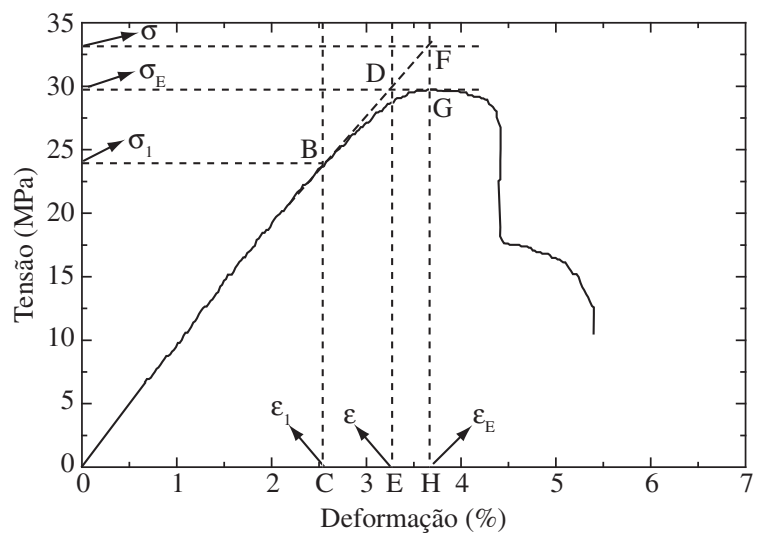

Figura 1. Diagrama esquemático tensão $(\sigma)$ - deformação $(\varepsilon)$ de material polimérico semi cristalino. 


\section{Cálculo da variação da energia livre de Helmholtz $(\Delta A)$}

Na região elástica da curva tensão - deformação, a variação da energia de Helmholtz por unidade de área da seção transversal do corpo de prova pode ser calculada a partir do trabalho útil realizado, $\mathrm{dw}=\mathrm{f}$ dl. Definindo os termos:

$\sigma_{\mathrm{T}}=$ tensão mecânica obtida experimentalmente;

área = área da seção transversal do corpo de prova;

1 = comprimento do corpo de prova durante o ensaio;

$1_{0}=$ comprimento inicial do corpo de prova;

$\varepsilon=$ deformação $=\left(1-1_{0}\right) / 1_{0}$; e

$\varepsilon_{\mathrm{E}}=$ deformação no escoamento.

Como $\sigma=$ f/área, $\mathrm{dl}=\mathrm{l}_{0} \mathrm{~d} \varepsilon$ e sendo $\mathrm{dw}=\mathrm{f}$ dl, então a variação da energia de Helmholtz por unidade de área da seção transversal na região elástica $\Delta \mathrm{A}$ é dada pela Equação 5:

$$
\Delta A=\int \frac{d w}{\text { área }}=\int f d l=\int \frac{\sigma_{T} \cdot \text { área.dl }}{\text { área }}=l_{0} \int_{0}^{\varepsilon_{\mathrm{E}}} \sigma_{T} d \varepsilon
$$

Sendo $\Delta \mathrm{A}$ calculado em unidade de energia por área.

$$
\text { A integral } \int_{0}^{\varepsilon_{\mathrm{B}}} \sigma_{\mathrm{T}} \mathrm{d} \varepsilon \text { é obtida a partir da área sob a curva }
$$

experimental tensão - deformação do ensaio mecânico de tração, calculada desde o início do ensaio até a deformação de escoamento, $\varepsilon_{\mathrm{E}}$, e, utilizando-se a Equação 3, obtém-se o valor de $\Delta \mathrm{A}$ a partir dos resultados experimentais do ensaio de tração.

\section{Cálculo da variação da energia interna $(\Delta U)$}

Considerando-se a deformação do material até o limite de elasticidade, ou seja, até o ponto de escoamento $\left(\sigma_{\mathrm{E}} ; \varepsilon_{\mathrm{E}}\right)$, se a energia deformacional armazenada até este ponto correspondesse apenas ao aumento na energia interna do polímero, então o valor máximo de $\Delta \mathrm{U}$ por unidade de volume seria dado pela área do triângulo $(0,0 ; \mathrm{D} ; \mathrm{E})$ da Figura 1 , ou seja:

Área $(0,0 ; \mathrm{D} ; \mathrm{E})=(1 / 2) \sigma_{\mathrm{E}} \varepsilon$

Mas $\varepsilon=\sigma_{\mathrm{r}} / \mathrm{E}$, então

Área $(0,0 ; \mathrm{D} ; \mathrm{E})=\sigma_{\mathrm{E}}^{2} / 2 \mathrm{E}$, que corresponde a unidades de energia/ volume.

Portanto, pode-se calcular a contribuição do armazenamento de energia interna em unidades de energia por área a partir dos valores experimentais de tensão de escoamento, $\sigma_{\mathrm{E}}$, e módulo elástico E, utilizando-se a Equação 4:

$$
\Delta \mathrm{U}=1_{0}\left(\sigma_{\mathrm{E}}^{2} / 2 \mathrm{E}\right)
$$

\section{Cálculo da variação da energia conformacional (- $T \Delta S)$}

Lembrando-se que $\Delta \mathrm{A}=\Delta \mathrm{U}-\mathrm{T} \Delta \mathrm{S}$, a partir dos valores calculados anteriormente de $\Delta \mathrm{A}$ e $\Delta \mathrm{U}$ pelas Equações 3 e 4 respectivamente, pode-se obter a contribuição relativa ao armazenamento de energia conformacional devido ao termo entrópico - $\mathrm{T} \Delta \mathrm{S}$ a partir da Equação 5:

$$
-\mathrm{T} \Delta \mathrm{S}=\Delta A-\Delta \mathrm{U}=1_{0} \int_{0}^{\varepsilon_{E}} \sigma_{\mathrm{T}} \mathrm{d} \varepsilon-1_{0}\left(\sigma_{\mathrm{E}}^{2} / 2 \mathrm{E}\right)
$$

\section{Dissipação de energia em relação ao comportamento perfeitamente elástico}

Com base na Equação 1, considerando-se que o polímero apresente o comportamento ideal de um cristal perfeito $(\Delta \mathrm{S}=0)$ até a deformação de escoamento $\varepsilon_{\mathrm{E}}$, na Figura 1 , o material armazenaria uma quantidade de energia elástica $\Delta \mathrm{A}=\Delta \mathrm{U}$, igual ao produto de $1_{0}$ pela área do triângulo $(0,0 ; \mathrm{F} ; \mathrm{H})$, cujo formalismo é semelhante ao anteriormente apresentado. Como a curva típica da resposta mecânica, do material semicristalino, apresenta um desvio da linearidade, a energia dissipada na região elástica devido ao desvio deste comportamento ideal (cristal perfeito) pode ser definida como um fenômeno de elasto-plasticidade, observado na região de pequenas deformações, entre 2 a 3,5\%.

A estimativa do valor desta energia pode ser realizado através do produto de $1_{0}$ pela área da figura BFG da Figura 1, que é igual à área do triângulo $(0,0 ; \mathrm{F} ; \mathrm{H})$ subtraída da área sob a curva tensão deformação.

Área $(0,0 ; \mathrm{F} ; \mathrm{H})=(1 / 2) \sigma \varepsilon_{\mathrm{E}}$

Mas $\sigma=\mathrm{E} \varepsilon_{\mathrm{E}}$, então

Área $(0,0 ; \mathrm{F} ; \mathrm{H})=\mathrm{E} \varepsilon_{\mathrm{E}}^{2} / 2$ que corresponde a unidades de energia/ volume, $\log$,

Dissipação de energia $=1_{0}\left(\mathrm{E} \varepsilon_{\mathrm{E}}^{2} / 2\right)-l_{0} \int_{0}^{\varepsilon_{E}} \sigma_{T} d \varepsilon$

Essa energia dissipada representa a quantidade de energia que poderia ser armazenada se o material se comportasse de maneira perfeitamente elástica (ausência do fenômeno elasto-plástico) até o ponto de máxima deformação na região elástica (área 0,$0 ; \mathrm{F} ; \mathrm{G}$ ), considerada no diagrama da Figura 1. A partir da Equação 6 e dos resultados do ensaio mecânico de tração é possível calcular esta dissipação de energia, conhecendo-se o módulo elástico E, a deformação no escoamento, $\varepsilon_{\mathrm{E}}$, e a área sob a curva tensão - deformação.

\section{Experimental}

\section{Materiais}

Amostra PE/PP: Mistura de poliolefinas recicladas à base de PEAD, PEBD e PP, provenientes do descarte doméstico. As poliolefinas recicladas eram de diferentes cores e suas porcentagens em massa estão apresentadas na Tabela 1.

Tabela 1. Porcentagem em massa de cada cor das poliolefinas recicladas.

\begin{tabular}{ccc}
\hline Cor & $\begin{array}{r}\text { Porcentagem em } \\
\text { massa }(\%)\end{array}$ \\
\hline 1 & Branco & 29,1 \\
2 & Azul & 16,2 \\
3 & Preto & 14,7 \\
4 & Amarelo & 14,0 \\
5 & Transparente & 12,9 \\
6 & Cinza & 4,8 \\
7 & Marrom & 4,6 \\
8 & Outros & 3,7 \\
\hline
\end{tabular}


Amostra PET: Mistura de poli(tereftalato de etileno) reciclado de garrafas de bebidas carbonatadas. A amostra PET foi constituída de uma mistura de 50\% em massa de PET reciclado verde e $50 \%$ em massa de $\mathrm{PET}$ reciclado incolor.

Compatibilizante: PP-g-MA (Polybond 3002 - Crompton), com 0,15 a $0,2 \%$ de anidrido maleico (MA).

Agente tenacificante: Poli(etileno-co-octeno-1) com teor de comonômero de 38\% - (Engage 8100 - DuPont Dow Elastomers).

Estabilizantes: 0,05 pcr de Irganox 1010, 0,1 pcr Irgafos 168 ou 0,1 pcr Irganox PS 802 e 0,6 pcr de Tinuvin 783 FDL foram adicionados em cada blenda.

\section{Composições das Blendas PET/poliolefinas reciclados}

Preparou-se $40 \mathrm{~g}$ de cada uma das composições da Tabela 2. Para se expressar a composição das blendas nas figuras deste trabalho utilizou-se a fração mássica em poliolefinas recicladas, que foi definida em relação à massa total de polímeros reciclados de acordo com a Equação 7:

Fração mássica de $=$

poliolefinas recicladas

\section{(massa de PE/PP).(100\%) \\ (massa de PE/PP + massa de PET)}

Na Equação 7 não estão presentes os aditivos e compatibilizantes, somente os materiais reciclados. Pode-se observar na Tabela 2 que em todas as blendas compatibilizadas a porcentagem de compatibilizante e do agente tenacificante total foi mantida constante e igual a $15 \%$.

As blendas de 1 a 7 da Tabela 2 não tiveram a adição de compatibilizante e são denominadas nas figuras deste trabalho como sem compatibilizante, enquanto as blendas de 8 a 15 são denominadas como com compatibilizante.

Tabela 2. Composições em massa das blendas preparadas.

\begin{tabular}{cccccc}
\hline & $\begin{array}{c}\text { PE/PP } \\
(\% \mathbf{g} / \mathbf{g})\end{array}$ & $\begin{array}{c}\text { PET } \\
(\boldsymbol{\%} \mathbf{g} / \mathbf{g})\end{array}$ & $\begin{array}{c}\text { PP-g-MA } \\
(\boldsymbol{\%} \mathbf{g} / \mathbf{g})\end{array}$ & $\begin{array}{c}\text { Engage } \\
(\boldsymbol{\%} \mathbf{g})\end{array}$ & $\begin{array}{c}\text { Fração } \\
\text { mássica em } \\
\mathbf{P E / P P} \\
(\% \mathbf{g} / \mathbf{g})\end{array}$ \\
\hline 1 & 0 & 100 & 0 & 0 & 0 \\
2 & 20 & 80 & 0 & 0 & 20 \\
3 & 40 & 60 & 0 & 0 & 40 \\
4 & 50 & 50 & 0 & 0 & 50 \\
5 & 60 & 40 & 0 & 0 & 60 \\
6 & 80 & 20 & 0 & 0 & 80 \\
7 & 100 & 0 & 0 & 0 & 100 \\
8 & 0 & 85 & 5 & 10 & 0 \\
9 & 20 & 65 & 5 & 10 & 23,5 \\
10 & 35 & 50 & 5 & 10 & 41,2 \\
11 & 40 & 45 & 5 & 10 & 47,1 \\
12 & 45 & 40 & 5 & 10 & 52,9 \\
13 & 50 & 35 & 5 & 10 & 58,8 \\
14 & 65 & 20 & 5 & 10 & 76,5 \\
15 & 85 & 0 & 5 & 10 & 100 \\
\hline
\end{tabular}

\section{Métodos}

Calorimetria Exploratória Diferencial (DSC): O equipamento utilizado nas análises de calorimetria exploratória diferencial foi um DSC 2100 TA Instruments. As curvas DSC das poliolefinas recicladas foram obtidas com amostras em formato de disco e massa de $5,43 \mathrm{mg}$, sob atmosfera de nitrogênio, a uma vazão de $50 \mathrm{~mL} \mathrm{~min}{ }^{-1}$, com porta amostra de alumínio sem tampa, no intervalo de temperaturas entre 20 e $350{ }^{\circ} \mathrm{C}$, razão de aquecimento de $10{ }^{\circ} \mathrm{C} \min ^{-1}$.

As curvas DSC para os PETs reciclados verde e incolor foram obtidas com amostras em formato de "flakes" e massa de amostra em torno de $10 \mathrm{mg}$, sob atmosfera de nitrogênio,

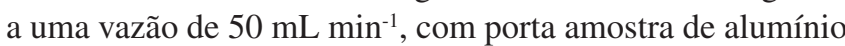
sem tampa, no intervalo de temperaturas entre 0 e $300{ }^{\circ} \mathrm{C}$, razões de aquecimento de $20^{\circ} \mathrm{C} \mathrm{min}^{-1}$, razão de resfriamento de $20{ }^{\circ} \mathrm{C}$ min $^{-1}$ controlada por um sistema LNCA, sem registro do resfriamento.

Mistura: As blendas sem e com compatibilizante foram preparadas em um reômetro de torque HAAKE Rheomix 600 p, em câmara de mistura com volume de $69 \mathrm{~cm}^{3}$, sob atmosfera de nitrogênio, temperatura constante de $260{ }^{\circ} \mathrm{C}$ nas paredes da câmara, rotores do tipo "roller" a uma rotação de $40,0 \mathrm{rpm}$. Os materiais foram misturados por 2,5 min, o qual foi um tempo suficiente para garantir que o torque atingisse um valor constante.

Preparo de amostras: Para a preparação de corpos de prova, na forma de filmes, inicialmente cada blenda foi seca a $90{ }^{\circ} \mathrm{C}$ por $4 \mathrm{~h}$. Os filmes foram obtidos por meio de moldagem por compressão em uma prensa CARVER a $260{ }^{\circ} \mathrm{C}$, pressão máxima de 2,0 ton $\mathrm{m}^{-2}$, tempo total de processamento de 1,5 min seguido de resfriamento em água a $25^{\circ} \mathrm{C}$.

Ensaios Mecânicos sob Tração: Utilizou-se nos ensaios mecânicos sob tração uma máquina EMIC DL2000 acoplada a um computador com software de controle de ensaio mecânico MTest Versão 2.00. Os ensaios mecânicos sob tração em filmes seguiram a norma ASTM D882 - $90^{[28]}$, com exceção do comprimento do corpo de prova que foi inferior ao estabelecido na norma. As dimensões dos corpos de prova foram: comprimento inicial $1_{0}=40,0 \mathrm{~mm}$, largu$\mathrm{ra}=8,0 \mathrm{~mm}$ e espessuras de $200 \pm 20 \mu \mathrm{m}$. A velocidade do ensaio utilizada foi de $5 \mathrm{~mm} \mathrm{~min} \mathrm{~m}^{-1}$. Os resultados foram obtidos a partir de curvas tensão $(\sigma)$ - deformação $(\varepsilon)$ e são as médias de pelo menos 5 corpos de prova no formato de fitas retirados de dois filmes distintos. A determinação das áreas sob a curva tensão - deformação foram efetuadas com auxílio de um planímetro.

Microscopia Eletrônica de Varredura (MEV): Para a observação da superfície de fratura criogênica das blendas utilizou-se um Microscópio Eletrônico de Varredura Zeiss DSM 940A - Oxford Instruments, com tensão de $15 \mathrm{kV}$ e ampliações de 500 vezes. 


\section{Resultados e Discussão}

\section{Calorimetria exploratória diferencial (DSC) dos materiais reciclados}

A partir da caracterização por DSC, as poliolefinas recicladas (PE/PP) apresentaram uma larga faixa de fusão entre 75 e $135^{\circ} \mathrm{C}$, com pico de fusão em $128,6{ }^{\circ} \mathrm{C}$, correspondente ao polietileno de alta densidade e polietileno de baixa densidade, e pico de fusão em $161,9^{\circ} \mathrm{C}$, correspondente ao polipropileno. Realizou-se uma estimativa do percentual de polipropileno na mistura PE/PP a partir da Equação 8, proposta por Camacho e Karlsson ${ }^{[29]}$ em que estes autores apresentam uma correlação entre o $\Delta \mathrm{H}$ de fusão do $\mathrm{PP}$ e a fração mássica de PP $\left(X_{\mathrm{PP}}\right)$ em blendas PEAD/PP.

$$
\Delta \mathrm{H} \text { de fusão do } \mathrm{PP}=0,6892 \cdot \mathrm{X}_{\mathrm{PP}}
$$

$\mathrm{O}$ valor obtido para o $\Delta \mathrm{H}$ de fusão do $\mathrm{PP}$, neste trabalho, foi de $5,48 \mathrm{~J} \mathrm{~g}^{-1}$ de blenda e utilizando-se a Equação 8 estimou-se um valor de fração mássica de PP na faixa de $8,0 \%$ nas poliolefinas recicladas.

A partir de caracterização das amostras de PET por calorimetria exploratória diferencial (DSC), determinaram-se as temperaturas de fusão, $\mathrm{T}_{\mathrm{m}}$, para o PET incolor e verde que foram respectivamente 182,6 e $248,6{ }^{\circ} \mathrm{C}$ e 169,6 e $250,1^{\circ} \mathrm{C}$. As menores temperaturas de fusão correspondem à fração de cristais formados a partir de cadeias com menor massa molar.

As temperaturas de transição vítrea, $\mathrm{T}_{\mathrm{g}}$, para o PET incolor e verde foram de $71,4^{\circ} \mathrm{C}$ e $70,8^{\circ} \mathrm{C}$ respectivamente.

\section{Variação da função trabalho de Helmholtz $(\Delta A)$, da energia} interna $(\Delta U)$ e da energia conformacional $(-T \Delta S)$

A partir dos resultados dos ensaios mecânicos de tração para cada composição das blendas, foram calculados os valores das áreas sob a curva tensão - deformação até a deformação de escoamento, $\varepsilon_{\mathrm{E}}$, a tensão de escoamento, $\sigma_{\mathrm{E}}$, e o módulo elástico, E. Utilizando-se as Equações 3, 4 e 5 obteve-se respectivamente os valores de $\Delta \mathrm{A}, \Delta \mathrm{U}$ e - $\mathrm{T} \Delta \mathrm{S}$.

As Figuras 2, 3 e 4 apresentam respectivamente os valores de $\Delta \mathrm{A}, \Delta \mathrm{U}$ e $-\mathrm{T} \Delta \mathrm{S}$ que foram calculados para cada blenda estudada.

Observa-se na Figura 2 o aumento da energia elástica armazenada para as blendas compatibilizadas, resultado do efeito do compatibilizante em aumentar a adesão interfacial entre as fases e a transmissão de energia mecânica de uma fase à outra. Como o PP-g-MA apresenta sítios apolares (PP) e polares (MA), as interações entre as fases PET e poliolefinas aumentam, levando a um ganho na absorção de energia elástica $(\Delta \mathrm{A})$ nas blendas compatibilizadas.

$\mathrm{Na}$ Figura 3, observa-se que o valor de $\Delta \mathrm{U}$ atinge um valor aproximadamente constante, independente da composição, para as blendas sem compatibilizante, sendo ligeiramente superior para as blendas com compatibilizante. Isto sugere que o material é capaz de armazenar energia elástica aumentando sua energia interna até um valor máximo. $\mathrm{O}$ valor de $\Delta \mathrm{U}$ pode estar relacionado à energia interfacial,

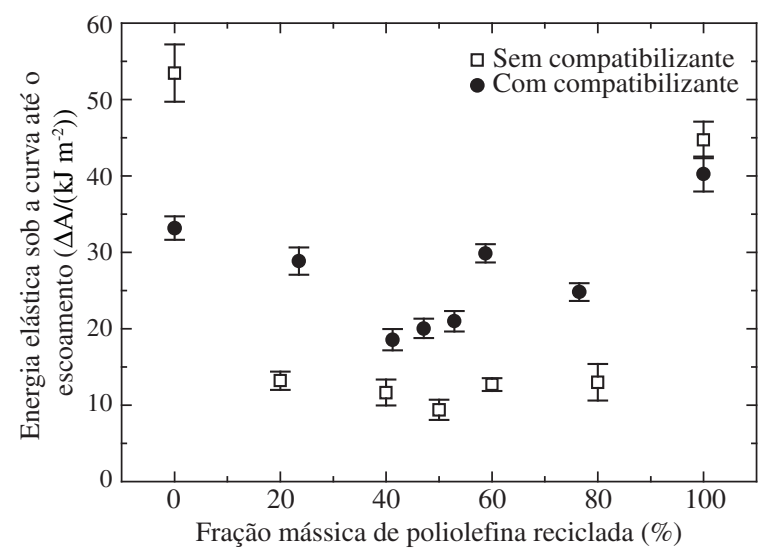

Figura 2. Diagrama da Variação da Energia de Helmholtz $\Delta \mathrm{A}$ (Energia Elástica sob a curva tensão - deformação até o escoamento) - Composição das Blendas PET/Poliolefinas reciclados.

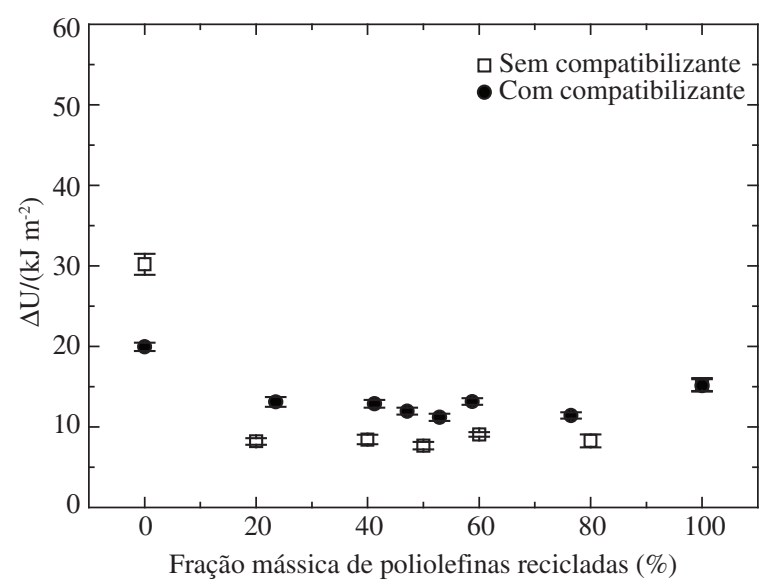

Figura 3. Diagrama da variação da energia interna $\Delta U$ (na região elástica) - Composição das Blendas PET/Poliolefinas recicladas.

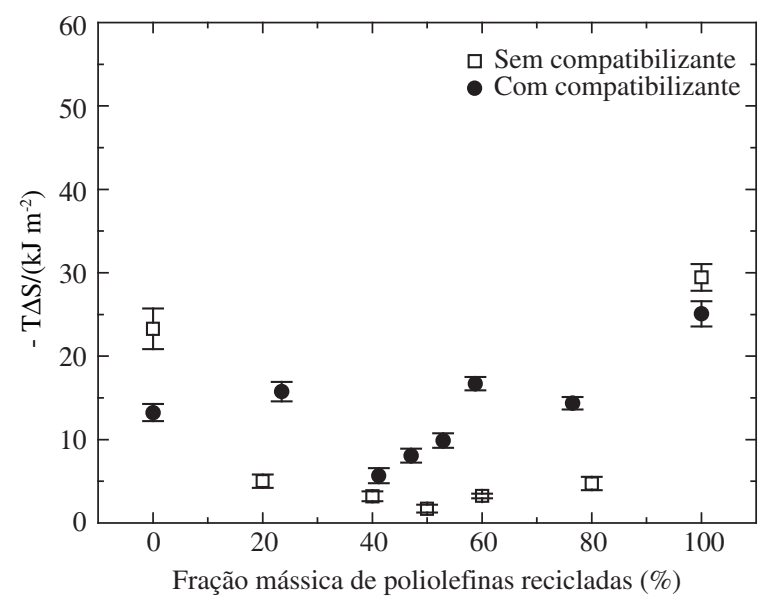

Figura 4. Diagrama de - T $\Delta \mathrm{S}$ (na região elástica) - Composição das Blendas $\mathrm{PET} /$ Poliolefinas recicladas.

com dependência apenas dos tipos de interação polímeropolímero e não da concentração dos polímeros. A presença do compatibilizante promove um aumento do valor de $\Delta \mathrm{U}$, o que mostra uma melhoria na interação na interface entre os polímeros imiscíveis. Este resultado é importante, pois se 
comprovado para outros pares de polímeros, abre a perspectiva para uma nova metodologia de correlação entre a energia interfacial em polímeros distintos (pares de polímeros ou um mesmo polímero com diferentes graus de cristalinidade) e a variação na energia interna na região elástica durante o ensaio mecânico de tração.

Na Figura 4, observa-se o armazenamento de energia elástica por variação da entropia conformacional - $\mathrm{T} \Delta \mathrm{S}$ com a composição. Nota-se que para as blendas sem compatibilizante, o valor de - T $\Delta \mathrm{S}$ é baixo, e a presença do compatibilizante aumenta este valor. Este mecanismo de armazenamento de energia elástica ocorre devido à transmissão de energia deformacional de uma fase para outra, o que acontece de maneira marcante na presença de compatibilizante, na região rica em poliolefina.

\section{Dissipação de energia em relação ao comportamento perfeitamente elástico}

Utilizando-se a Equação 6 e os resultados dos ensaios mecânicos de tração para cada composição das blendas, foram calculados os valores das áreas sob a curva tensão - deformação até a deformação de escoamento, $\varepsilon_{\mathrm{E}}$, a deformação no escoamento, $\varepsilon_{\mathrm{E}}$, o módulo elástico, $\mathrm{E}$ e a dissipação de energia. Os resultados obtidos, para cada blenda estudada, estão apresentados na Figura 5.

Observa-se um aumento da dissipação de energia para as blendas compatibilizadas em relação às blendas sem compatibilizante, o que demonstra novamente a atuação do compatibilizante na interface em toda faixa de composições. É importante ressaltar que houve aumentos significativos tanto em energia elástica $(\Delta \mathrm{A})$ quanto em dissipação de energia principalmente na fase rica em poliolefinas.

A representação conjunta, para cada blenda estudada, da relação entre a energia armazenada pela mudança de entropia conformacional (- T $\Delta \mathrm{S}$ ) (Figura 4) e a dissipação de energia em relação ao comportamento perfeitamente elástico (Figura 5) está mostrada na Figura 6.

Pode-se observar que as blendas sem compatibilizante encontram-se em uma região de valores de - $T \Delta S$ inferiores a $5 \mathrm{~kJ} \mathrm{~m}^{-2}$ e valores de dissipação de energia inferiores a $2,5 \mathrm{~kJ} \mathrm{~m}^{-2}$. Ao se adicionar compatibilizante, ocorreu um aumento em - T $\Delta \mathrm{S}$ e em dissipação de energia para as blendas e os pontos deslocando-se para a região próxima a linha - T $\Delta \mathrm{S}=$ dissipação de energia. Conceitualmente esta igualdade representa o comportamento de uma borracha ideal. Notase que materiais de característica mais elastomérica, como as poliolefinas recicladas e da blenda PE/PP 85\%/Engage 10\%/ PP-g-MA 5\%, apresentam neste caso os maiores valores tanto de dissipação de energia quanto de - T $\Delta$ S. Já o material de característica mais rígida, como o PET reciclado, apresentou alto valor de - T $\Delta \mathrm{S}$ e baixo valor de dissipação de energia. No entanto a blenda com composição intermediária PE/PP 50\%/PET 35\% com compatibilizante se bem manteve o valor de - T $\Delta \mathrm{S}$ próximo daqueles da composição PET $100 \%$, apresentou um ganho significativo na dissipação de energia, aproximando-se do comportamento da borracha ideal.

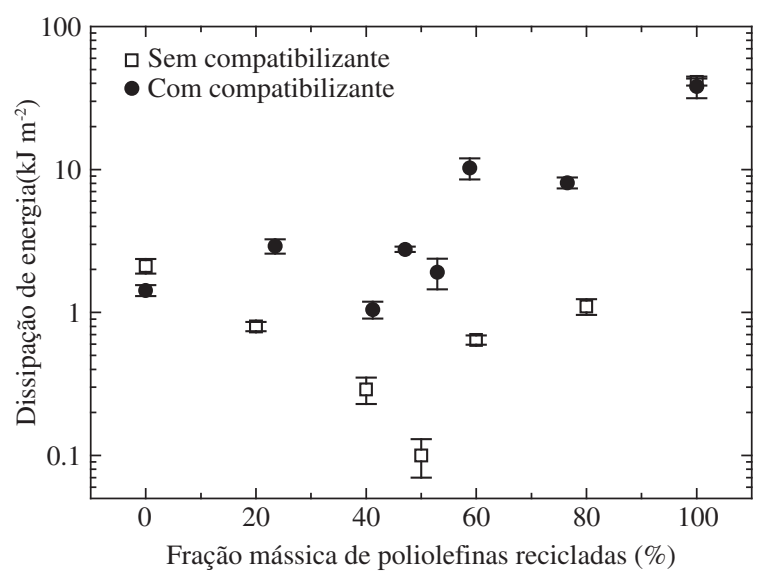

Figura 5. Diagrama Dissipação de energia - Composição das Blendas PET/ Poliolefinas recicladas.

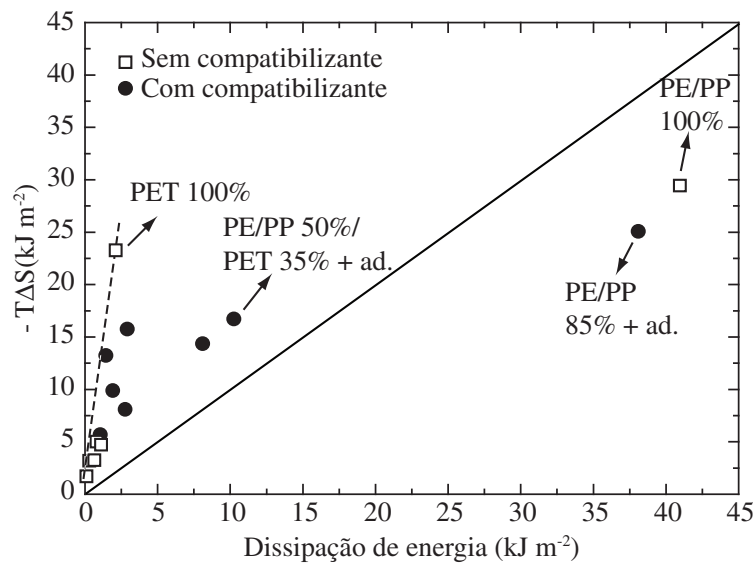

Figura 6. Diagrama - $\mathrm{T} \Delta \mathrm{S}$ - Dissipação de energia em ralação ao comportamento perfeitamente elástico.

\section{Microscopia eletrônica de varredura (MEV)}

Os resultados de MEV, comparando-se uma blenda rica em PET e uma blenda rica em poliolefinas, estão apresentados na Figura 7.

A partir das microscopias eletrônicas de varredura de uma blenda compatibilizada rica em PET (Figura 7a) e outra rica em poliolefinas (Figura 7b), pode-se observar que na região rica em poliolefinas ocorreu maior diminuição do tamanho da fase dispersa, devido provavelmente a atuação do compatibilizante, aumentando a interação entre as fases, o que contribui para melhor transferência de energia mecânica entre as fases distintas, corroborando os resultados da análise termodinâmica apresentada para a região elástica.

\section{Conclusões}

A partir da aplicação de um formalismo termodinâmico baseado na função trabalho de Helmholtz foi possível analisar o comportamento do armazenamento de energia elástica sob duas formas, através da variação da energia interna e da variação da entropia na região de comportamento elástico 


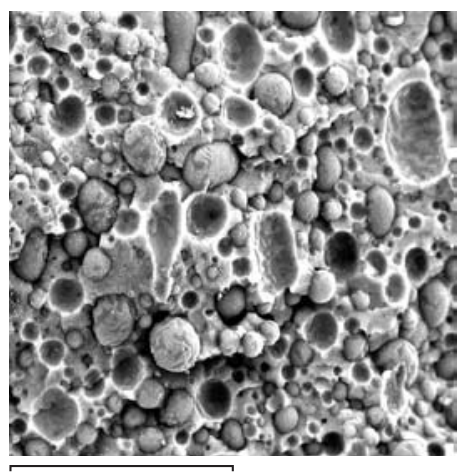

$90 \mu \mathrm{m}$

(a)

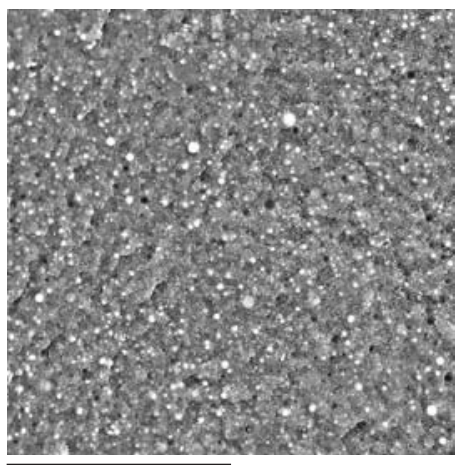

$90 \mu \mathrm{m}$

(b)

Figura 7. Microscopias Eletrônicas de Varredura (MEV) da superfície de fratura criogênica da massa das blendas do misturador de câmara interna com ampliação de 500 vezes. a) PE/PP 20\%/PET 65\%/Engage 10\%/ PP-g-MA 5\%; e b) PE/PP 65\%/PET 20\%/Engage 10\%/PP-g-MA 5\%.

dos materiais estudados. Analisou-se também a dissipação de energia relativa ao fenômeno elasto-plástico Para os sistemas estudados, observou-se que o efeito do compatibilizante é muito mais acentuado na região rica em poliolefinas. A análise termodinâmica foi corroborada pelos resultados obtidos via microscopia eletrônica de varredura.

A análise termodinâmica apresentada mostrou-se uma ferramenta útil e confiável e de baixo custo, para avaliar o efeito de compatibilização de sistemas poliméricos imiscíveis. No presente trabalho, particularmente para a avaliação do comportamento mecânico de diferentes composições de misturas de materiais "comoditties", reciclados.

\section{Agradecimentos}

Ao CNPq pela bolsa de doutorado para o Eng. José Manoel Marconcini e FAI-UFSCar pelo auxílio financeiro.

\section{Referências Bibliográficas}

1. Lusinchi, J. M.; Boutevin, B.; Torres, N. \& Robin, J. J. - J. Appl. Polym. Sci., 79, p. 874 (2001).

2. Pang, Y. X.; Jia, D. M.; Hu, H. J.; Horston, D. J. \& Song, M. - Polymer, 41, p. 357 (2000).
3. Utracki, L. A. - "Polymer Alloys and Blends: Thermodynamics and Rheology", Hanser Publishers, Oxford University Press, New York, (1989).

4. Paul, D. R. \& Bucknall, C. B. (Eds.) - "Polymer Blends Volume 1: Formulation", John Willey \& Sons, New York, 2000.

5. Dimitrova, T. L.; La Mantia, F. P.; Pilati, F.; Toselli, M.; Valenza, A. \& Visco, A. - Polymer, 41, p. 4817 (2000).

6. Pluta, M.; Zbigniew, B.; Pawlak, A.; Galeski, A. \& Pracella, M. - J. Appl. Polym. Sci., 82, p. 1423, (2001).

7. Mallette, J. G.; Quej, L. M.; Marquez, A. \& Manero, O. - J. Appl. Polym. Sci., 81, p. 562, (2001).

8. Carté, T. L. \& Moet, A. - J. Appl. Polym. Sci., 48, p. 611 (1993).

9. Torres, N.; Robin J. J. \& Boutevin, B. - J. Appl. Polym. Sci., 81, p. 2377 (2001).

10. Boutevin, B.; Lusinchi, J. M.; Pietrasanta, Y. \& Robin, J. J. - Polym. Eng. Sci., 36, p. 879 (1996).

11. Utracki, L. A. - Polym. Eng. Sci., 35, p. 2 (1995).

12. Traugott, T. D.; Barlow, J. W. \& Paul, D. R. - J. Appl. Polym. Sci., 28, p. 2947 (1983).

13. Halder, R. S., Deopura, B. L. \& Misra, A. - Polym. Eng. Sci., 29, p. 1766 (1989).

14. Dagli, S. S. \& Kamdar, K. M. - Polym. Eng. Sci., 34, p. 1709 (1994).

15. Ballauri, B.; Trabuio, M. \& La Mantia, F. P - “Compatibilization of recycled polyethyleneterephthalate/polypropylene blends using a functionalized rubber" in: La Mantia, F. P. (ed.) - "Recycling of PVC and Mixed Plastic Waste", Chem Tec Publishing, Canada, p. 77-91 (1996).

16. La Mantia, F. P. - "Recycling of post-consumer plastic containers for liquids" in: La Mantia, F. P. (ed.) - "Recycling of PVC and Mixed Plastic Waste", Chem Tec Publishing, Canada, p. 93-116 (1996).

17. Pacheco, E. B. \& Hemais, C. A. - Polímeros: Ciência e Tecnologia, 9(4), p. 59 (1999).

18. Santos, A. S. F.; Agnelli, J. A. M. \& Manrich, S. - Polímeros: Ciência e Tecnologia, 9(4), p. 189 (1999).

19. Iñiguez, C. G.; Michel, V. M.; González-Romero, V. M. \& González-Nuñez, R. - Polym. Bull., 45, p. 295 (2000).

20. Guerrero, C.; Lozano, T.; González, V. \& Arroyo, E. - J. Appl. Polym. Sci., 82, p. 1382 (2001).

21. Kim, D. H.; Park, K. Y.; Kim, J. Y. \& Suh, K. D. - J. Appl. Polym. Sci., 78, p. 1017 (2000).

22. Papke, N. \& Karger-Kocsis, J. - Polymer, 42, p. 1109 (2001).

23. Shertukde, V. V. \& Kale, D. D. - J. Polym. Mater., 19, p. 119 (2001).

24. Avila, A. F.; Rodrigues, P. C. M.; Santos, D. B. \& Faria, A. C. A. - Mater. Charact., 50, p. 281 (2003).

25. Xu, H. S.; Li, Z. M.; Yang, S. Y.; Pan, J. L.; Yang, W. \& Yang, M. B. - Polym. Eng. Sci., 45, p. 1231 (2005).

26. Herrera-Franco, P. J.; Henández-Sánchez F.; Adem, E. \& Burillo, G. - Polym. Bull., 56, p. 47 (2006).

27. Tager, A. "Physical Chemistry of Polymer", Mir Publishers, Moscou (1978).

28. ASTM D882-90 Standard test method for tensile properties of thin plastic sheeting, Annual Book of ASTM Standards (1991).

29. Camacho, W. \& Karlsson, S. - Polym. Eng. Sci., 41, p. 1626 (2001).

Enviado: 09/03/06

Reenviado: 03/07/06

Aprovado: 20/09/06 